\title{
ESTIMASI KANDUNGAN KARBON (C) PADA SERASAH DAUN MANGROVE DI DESA LANSA, KECAMATAN WORI, KABUPATEN MINAHASA UTARA
}

\author{
(Estimation of Carbon (C) Content in Mangrove Leaves From Lansa Village, Wori Sub- \\ District, North Minahasa District)
}

\author{
Fadli Tidore ${ }^{1^{*}}$, Antonius Rumengan ${ }^{1}$, Calvyn F.A. Sondak ${ }^{1}$, \\ Remy E.P. Mangindaan ${ }^{1}$, Heard C.C. Runtuwene ${ }^{1}$, Silvester B. Pratasik ${ }^{2}$ \\ ${ }^{1)}$ Program Studi Ilmu Kelautan Fakultas Perikanan dan IImu Kelautan, \\ Universitas Sam Ratulangi, Manado. \\ ${ }^{2)}$ Program Studi Manajemen Sumber Daya Perairan Fakultas Perikanan dan Ilmu Kelautan, \\ Universitas Sam Ratulangi, Manado. \\ "E-mail: tidorefad@gmail.com
}

\begin{abstract}
Global warming is one of the environmental issues related to climate change. Coastal blue carbon ecosystems such as mangrove and seagrass have ability to combat global warming. Mangrove ecosystem has an important ecological function in efforts to mitigate global warming, by carbon storage. This study was done in Lansa Village mangrove forest and focused on mangrove leaf litter. The purpose of this study was to estimate carbon content in mangrove leaf litter. Leaf litter samples were collected by using a $1 \times 1 \mathrm{~m}^{2}$ litter trap, which was made of black nylon with a mesh size of about $0.2 \mathrm{~cm}, 8$ traps were put under mangrove trees canopy, with a height of $1.5 \mathrm{~m}$ above sea level or at the highest tide. The samples were taken and observed every 7 days. The samples were analyzed by using Dry-Ash Method. The results showed that the average litter production of gram wet weight (Gbb) and gram dry weight obtained during the study were $122.97 \mathrm{gbb} \mathrm{m}^{2} / 28$ days, $4.39 \mathrm{gbb} \mathrm{m}^{2} / 28$ days, $47.69 \mathrm{gbk} \mathrm{m}^{2} / 28$ days, $1.83 \mathrm{gb} \mathrm{m}^{2} /$ day. The average of mangrove leaf litter biomass is $30.12 \mathrm{~g} \mathrm{~m}^{2}$. The highest amount of carbon storage in mangrove litter was $19.30 \mathrm{gram} \mathrm{C.} \mathrm{The} \mathrm{average} \mathrm{value} \mathrm{of} \mathrm{the}$ percentage of carbon content of all plots was $31.38 \%$ per day. Based on these results the estimated amount of carbon removal in mangrove leaves was $2.16 \mathrm{t} \mathrm{C} \mathrm{ha-1} \mathrm{y-1} \mathrm{or} 337.18 \mathrm{t} \mathrm{C} \mathrm{y-}$ 1. and $1,237.45$ t CO2 y-1.
\end{abstract}

Keywords : mangrove, estimation of carbon content of mangrove litter, lansa village.

Ekosistem mangrove memiliki fungsi ekologis yang sangat penting dalam upaya mitigasi pemanasan global, yakni sebagai penyerap dan penyimpan karbon Hutan mangrove juga memiliki peran sebagai penyerap karbon dioksida $\left(\mathrm{CO}_{2}\right)$ dari udara sehingga sangat berguna untuk mitigasi perubahan iklim. Tujuan dari penelitian ini adalah untung mengestimasi kandungan karbon pada serasah daun mangrove di hutan mangrove Desa Lansa, Kecamatan Wori, Kabupaten Minahasa Utara. penelitian ini dilakukan menggunakan metode litter trap yang berukuran $1 \times 1 \mathrm{~m}^{2}$, yang terbuat dari nylon berwarna hitam dengan ukuran mata jaring (mesh size) sekitar $0,2 \mathrm{~cm}$, sebanyak 8 buah dipasang di bawah kanopi pohon mangrove, dengan ketinggian $1,5 \mathrm{~m}$ di atas permukaan air laut atau pada pasang tertinggi untuk menampung jatuhnya serasah dan diamati setiap 7 hari. Hasil penelitian diperoleh rata-rata produksi serasah gram berat basah (Gbb) dan gram berat kering yang didapat selama penelitian, sebesar $122,97 \mathrm{gbb} / \mathrm{m}^{2} / 28 \mathrm{hr}, 4,39 \mathrm{gbb} / \mathrm{m}^{2} / \mathrm{hr}, 47,69 \mathrm{gbk} / \mathrm{m}^{2} / 28 \mathrm{hr}, 1,83 \mathrm{gbk} / \mathrm{m}^{2} / \mathrm{hr}$. rata-rata biomassa serasah daun mangrove sebesar 41,07. Jumlah simpanan karbon tertinggi pada serasah mangrove sebesar 19,30 gram C. Nilai rata-rata persentase kandungan karbon dari semua plot adalah sebesar $31,38 \%$ per hari, berdasarkan hasil penelitian jumlah estimasi kandungan karbon yang tersimpan pada serasah daun mangrove 2,16 ton/ha/tahun.

Kata kunci: mangrove, estimasi kandungan karbon serasah mangrove, desa lansa.

\section{PENDAHULUAN}

Ekosistem mangrove merupakan salah satu ekosistem wilayah pesisir yang sangat potensial sebagai penyedia unsur hara bagi ekosistem mangrove dan perairan pesisir sekitarnya (Haris, et al., 
2012; Rumengan et al., 2018). Ekosistem mangrove sebagai penyedia unsur hara juga sebagai penyangga antara ekosistem daratan dan lautan. Oleh karena itu ekosistem mangrove berperan penting terhadap keberlanjutan kehidupan berbagai biota yang hidup di wilayah pesisir, karena ekosistem mangrove sebagai tempat memijah, pembesaran, makan dan berlindung (Kathiresan dan Bingham, 2001; Paruntu et al., 2017).

Fungsi ekologis hutan mangrove sangat penting dalam upaya mitigasi pemanasan global, yakni sebagai penyimpan karbon terbaik dibanding semua tipe hutan lainnya di bumi (Zulkarnain, et al., 2016; Verisandria et al., 2018). Hutan mangrove memiliki peran sebagai penyerap karbon dioksida $\left(\mathrm{CO}_{2}\right)$ dari udara sehingga sangat berguna untuk mitigasi perubahan iklim. (Wiarta, et al., 2017).

Pemanasan global merupakan salah satu isu lingkungan yang sangat penting dan saat ini menjadi perhatian berbagai pihak. Penyebab utama terjadi pemanasan global adalah meningkatnya gas-gas rumah kaca, terutama sisa pembakaran yang mengudara seperti karbon dioksida dan metana. Pemanasan global mempunyai dampak yang sangat besar terhadap dunia dan kehidupan semua makhluk hidup di muka bumi (Manuri, et al., 2011). Selain itu peran hutan mangrove sebagai penyerap dan penyimpan karbon sangat penting dalam rangka mengatasi masalah efek gas rumah kaca yang mengakibatkan pemanasan global (Yuniawati, et al., 2011). Serasah mangrove yang jatuh menjadi sumber nutrien biota perairan dan unsur hara yang sangat penting menentukan produktivitas perikanan laut (Rudiansyah, et al., 2013). Menurut Dharmawan, et al., (2016), serasah daun sebagai komponen utama dalam produktivitas primer mangrove merupakan sumber karbon penting dalam proses dekomposisi.

Walaupun memiliki kemampuan untuk menyerap karbon, penelitian mengenai kandungan karbon dalam serasah mangrove masih belum banyak dilakukan di Sulawesi Utara. Penelitian kandungan karbon mangrove umumnya difokuskan pada biomasa pohon dan sedimen (Sondak, 2015; Bachmid et al.
2018; Verisandria et al. 2018). Berdasarkan permasalahan di atas, maka dilakukan penelitian mengenai estimasi kandungan karbon yang tersimpan pada serasah mangrove untuk mengetahui seberapa besar hutan mangrove di Desa Lansa, Kecamatan Wori, Kabupaten Minahasa Utara mampu menyerap $\mathrm{CO}_{2}$ dari udara, sehingga hal tersebut dapat menunjang kegiatan pengelolaan kawasan secara berkelanjutan dalam kaitannya dengan pengurangan konsentrasi $\mathrm{CO}_{2}$ di atmosfer

\section{METODE PELAKSANAAN}

Penelitian ini dilakukan selama 1 bulan dari bulan April-Mei 2018 di hutan mangrove Desa Lansa, Kecamatan Wori, Kabupaten Minahasa Utara. Pengeringan sampel dilakukan di Laboratorium Biologi Molekuler \& Farmasitika Laut, Fakultas Perikanan dan IImu Kelautan, Universitas Sam Ratulangi Manado, dan pengabuan sampel dilakukan di UPT Laboratorium Terpadu Universitas Sam Ratulangi Manado. Pengambilan data dalam penelitian ini dilakukan tanpa merusak objek penelitian (purpose sampling).

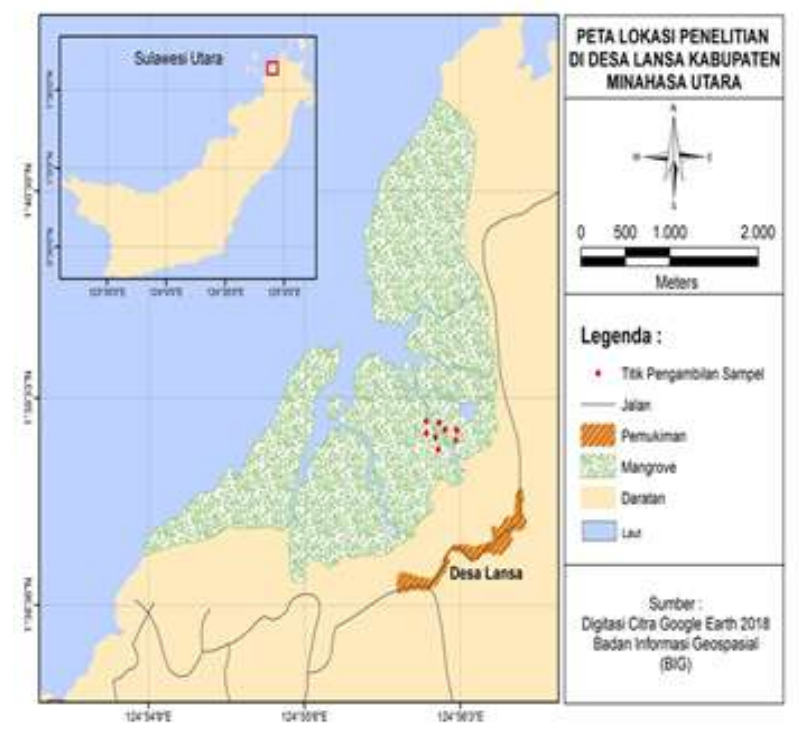

Gambar 1. Lokasi Penelitian.

Metode yang umum digunakan untuk menangkap guguran serasah di hutan mangrove dalam waktu tertentu adalah dengan litter-trap (jaring penangkap serasah). Litter-trap merupakan jaring penangkap serasah yang berukuran $1 \times 1$ $\mathrm{m}^{2}$, yang terbuat dari nylon berwarna hitam dengan ukuran mata jaring (mesh size) sekitar $0,2 \mathrm{~cm}$. Pengukuran produksi 
serasah dilakukan pada serasah yang tertampung dalam perangkap serasah setiap 7 hari. Berat basah serasah diperoleh setelah ditimbang sebelum dioven. Berat kering serasah diperoleh setelah dikeringkan dalam oven pada suhu $80^{\circ} \mathrm{C}$ sampai mencapai berat konstan. Analisis produksi serasah dilakukan menggunakan Persamaan Hamidy, et al. (2002).

Berat Basah $=(\mathrm{Gbb} / \mathrm{m} 2 / \mathrm{hari})$

Ket.: gbb (Gram berat basah); $\mathrm{m}^{2} /$ hari (Meter kuadrat per hari).

Rudiansyah et al., (2013), menjelaskan bahwa prinsip dari metode pengabuan secara langsung (kering) yaitu dengan mengoksidasi semua zat organik pada suhu tinggi berkisar antara 500$600^{\circ} \mathrm{C}$ selama 5 jam. Adapun langkah analisis kadar abu adalah sebagai berikut: 1) Persiapkan cawan kosong sebagai tempat sampel dan timbang beratnya (B). 2) Sampel serasah yang telah diketahui berat keringnya (C) dimasukan dalam cawan yang telah disiapkan. 3) Cawan yang berisi sampel tersebut dimasukan dalam oven pembakar furnace dengan suhu $600^{\circ} \mathrm{C}$. 4) Sesudah 5 jam, sampel dikeluarkan dari oven pembakaran, 5) Selanjutnya sampel didinginkan selama 1 jam. 6).

Setelah itu sampel ditimbang kembali untuk mengetahui berat akhir $(A)$.

$$
\operatorname{Kadar} \mathrm{Abu}(\%)=\frac{\mathrm{A}-\mathrm{B}}{\mathrm{C}} \times 100 \%
$$

Ket.: A (Berat akhir Cawan + Sampel (gr)); B (Berat Awa Cawan (gr)); C (Berat Sampel (gr)).

Setelah nilai kadar bahan kering serasah dan kadar abu didapatkan maka kandungan karbon dapat diketahui dengan rumus sebagai berikut:

\section{Kandungan karbon $(\mathrm{C})=$ \\ (Kadar bahan kering - Kadar abu)\%}

Setelah nilai kadar bahan kering serasah dan kadar abu didapatkan maka kandungan karbon dapat diketahui dengan rumus sebagai berikut:

$$
\text { Tolak BK= } \frac{\mathrm{BK}(\mathrm{g})}{\mathrm{BB}(\mathrm{g})} \times \text { Total BB }(\mathrm{g})
$$

Setelah nilai biomassa didapat, penentuan kandungan menurut karbon dapat dihitung dengan mengalikan total biomassa dengan 0,46 karena konsentrasi C dalam bahan organik adalah $46 \%$ (Chanan 2012). Perhitungan dapat dilakukan dengan rumus sebagai berikut: Estimasi jumlah karbon = biomassa $\times 0,46$.

\section{HASIL DAN PEMBAHASAN}

\section{Produksi Serasah Mangrove}

Produksi serasah mangrove per plot selama empat minggu pengamatan yang terbagi pada 8 penampung serasah (litter trap) disajikan pada gambar 2. Produksi serasah merupakan bagian yang penting dalam transfer bahan organik dari vegetasi ke dalam tanah. Unsur hara yang dihasilkan dari proses dekomposisi serasah di dalam tanah sangat penting dalam pertumbuhan mangrove dan sebagai sumber detritus bagi ekosistem laut dan estuari dalam menyokong kehidupan berbagai organisme akuatik (Zamroni dan Immy, 2008).

Data hasil pengambilan sampel serasah mangrove pada 8 penampung serasah yang dilakukan selama 28 hari dengan jarak waktu pengambilan selama 7 hari dapat dilihat pada gambar 2. Rata-rata hasil produksi serasah gram berat basah (Gbb) dan gram berat kering yang didapat selama penelitian, adalah sebesar 122,97 $\mathrm{gbb} / \mathrm{m}^{2} / 28 \mathrm{hr}, \quad 4,39 \mathrm{gbb} / \mathrm{m}^{2} / \mathrm{hr}, \quad 47,69$ $\mathrm{gbk} / \mathrm{m}^{2} / 28 \mathrm{hr}, 1,83 \mathrm{gbk} / \mathrm{m}^{2} / \mathrm{hr}$.

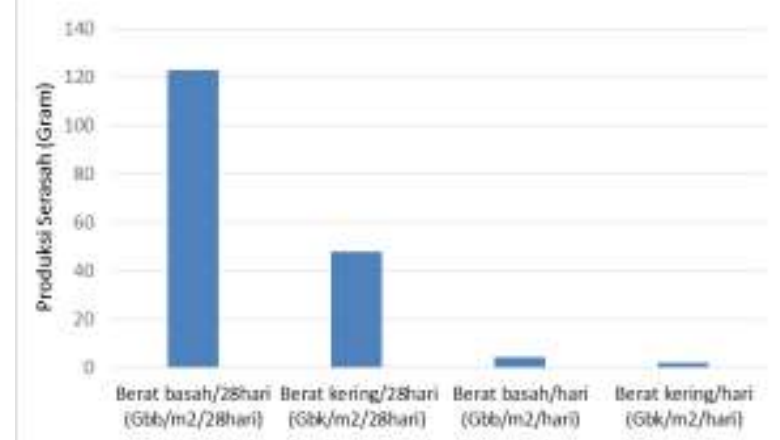

Gambar 2. Laju produksi serasah mangrove Desa Lansa, Kecamatan Wori, Kabupaten Minahasa Utara.

\section{Biomassa Serasah Mangrove}

Hasil perhitungan biomassa pada serasah daun mangrove (Gambar 3), $A$. marina, dan $R$. mucronata memiliki ratarata biomassa terendah di Plot 2 dengan nilia 2,87 $\mathrm{gram} / \mathrm{m}^{2} /$ hari sedangkan rata-rata jumlah biomassa tertinggi ada pada Plot 4 yaitu sebesar $5,87 \mathrm{gram} / \mathrm{m}^{2} /$ hari. Rata-rata 
biomassa serasah mangrove Desa Lansa Kecamatan Wori Kabupaten Minahasa Utara 4,30 gram $/ \mathrm{m}^{2} /$ hari. Hasil ini lebih tinggi dari Zamroni dan Rohyani (2008) yang mendapatkah biomassa serasah mangrove di Pantai Teluk Sepi, Lombok Barat sebesar 2,98 gram $/ \mathrm{m}^{2} / \mathrm{hari}$.

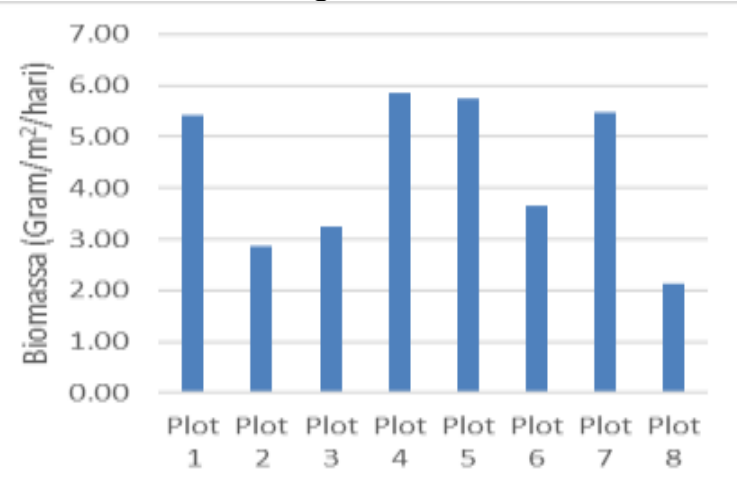

Gambar 3. Biomassa Serasah Mangrove Desa Lansa Kecamatan Wori Kabupaten Minahasa Utara.

\section{Kandungan Karbon Serasah Mangrove}

Hasil estimasi kandungan karbon pada serasah mangrove (gambar 4), ratarata kandungan karbon (C) tertinggi terdapatpada plot 4 yaitu sebesar 19,30 gram $\mathrm{C}$, dan kandungan karbon terendah berada pada plot 2 adalah sebesar 9,43 gram C Jumlah simpanan karbon (C) tertinggi ada pada Plot 4 sebesar 19,30 gram C dengan rata-rata C serasah 467,37 gram karbon $\mathrm{C}$.

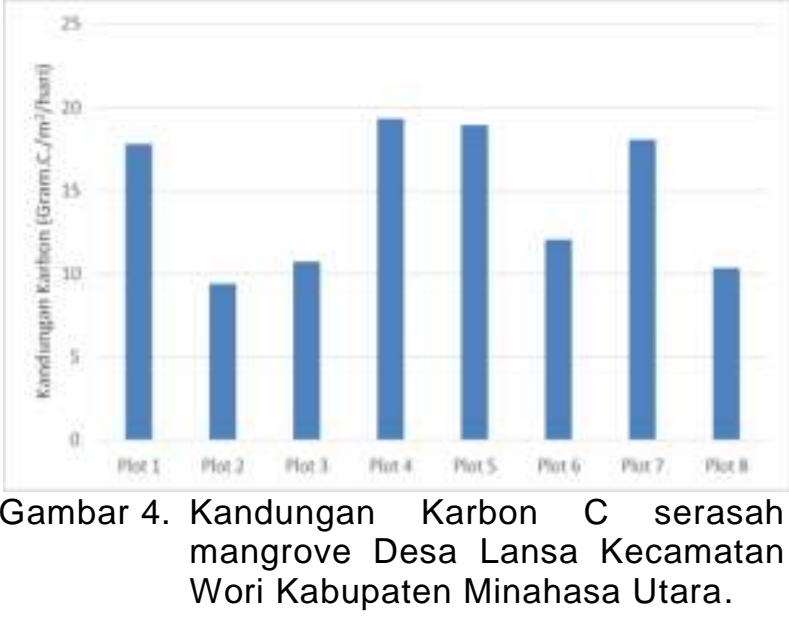

\section{Persentase Kandungan Karbon Serasah Mangrove}

(C)

Kandungan karbon pada tanaman menggambarkan berapa besar tanaman dapat mengikat $\mathrm{CO}_{2}$ dari udara. Sebagian karbon akan menjadi energi untuk proses fisiologi tanaman dan sebagian masuk ke dalam struktur tumbuhan dan menjadi bagian dari tumbuhan, misalnya selulosa yang tersimpan pada batang, akar, ranting dan daun (Heriyanto dan Endro,2012). Dari hasil laju produksi serasah mangrove, maka dilakukan perhitungan kandungan karbon pada sampel serasah yang telah dikumpulkan selama 28 hari yang di ambil setiap 7 hari. Nilai rata-rata persentase kandungan Karbon serasah mangrove pada tiap plot penelitian di hutan mangrove Desa Lansa disajikan pada Gambar 5. Nilai ratarata kandungan karbon dari semua plot adalah sebesar $31,38 \%$ per jika dibandingkan dengan hasil penelitian Rudiansyah, et al., (2013), yang mendapatkan rata-rata persentase kandungan karbon pada serasah mangrove di Perairan Kampung Gisi Desa Tembeling, Kecamatan Teluk Bintan, Kabupaten Bintan, Provinsi Kepulauan Riau sebesar $50,742 \% \mathrm{C} / \mathrm{hr}$. Maka kandungan karbon (C) serasah mangrove pada penelitian ini dikategorikan masih rendah, menurut asumsi Supriharyono (2009), menyatakan bahwa $45 \%$ sampai $50 \%$ bahan kering tanaman terdiri dari kandungankarbon.

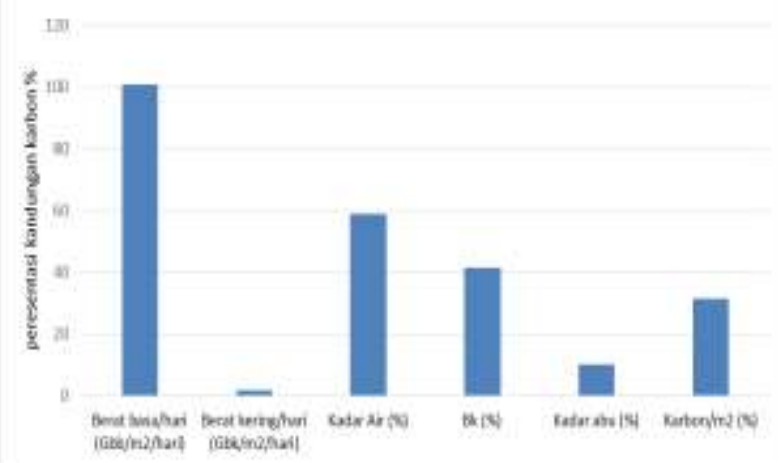

Gambar 5. Peresentase kandungan karbon (C) serasah mangrove.

\section{Estimasi Kandungan Karbon Pada Serasah daun Mangrove}

Dari analisis data tersebut dapat diketahui bahwa rata-rata estimasi kandungan karbon pada serasah daun mangrove di Desa Lansa Kecamatan Wori Kabupaten Minahasa Utara sebesar 2,16 ton/ha/tahun atau 337,7 ton/tahun (Tabel 1). Menurut Hidayanto, et al. (2004), semakin besar vegetasi pada hutan mangroveakan memiliki kemampuan besar untuk Menghasilkan seresah organik yang merupakan penyusun utama bahan organik dalam tanah. Hal tersebut dapat diartikan bahwa produksi serasah mempengaruhi 
simpanan karbon pada serasah daun mangrove. Menurut Rosita, et al., (2013) Semakin rapat tegakan pohon mangrove jumlah produksi serasah juga semakin banyak, maka kandungan karbon yang ada pada serasah juga semakin tinggi.

Tabel 1. Estimasi kandungan karbon pada serasah mangrove di Desa Lansa Kecamatan Wori Kabupaten Minahasa Utara

\begin{tabular}{|c|c|c|c|c|c|c|c|}
\hline$\frac{\overline{0}}{\alpha}$ & 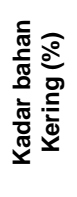 & 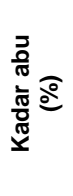 & 흥 & 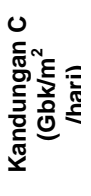 & 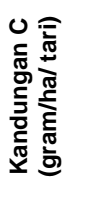 & 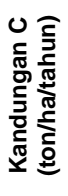 & 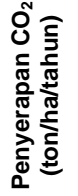 \\
\hline 1 & 47.62 & 8.52 & 39.10 & 1.06 & $10,578.2$ & 3.86 & 602.7 \\
\hline 2 & 31.89 & 7.29 & 24.60 & 0.35 & $3,526.0$ & 1.29 & 200.9 \\
\hline 3 & 37.38 & 9.07 & 28.31 & 0.46 & $4,606.9$ & 1.68 & 262.5 \\
\hline 4 & 35.83 & 11.60 & 24.23 & 0.36 & $3,554.4$ & 1.30 & 202.5 \\
\hline 5 & 43.99 & 10.40 & 33.59 & 0.54 & $5,437.2$ & 1.98 & 309.8 \\
\hline 6 & 46.39 & 10.76 & 35.63 & 1.01 & $10,084.6$ & 3.68 & 574.6 \\
\hline 7 & 44.82 & 12.35 & 32.47 & 0.45 & $4,453.7$ & 1.63 & 253.8 \\
\hline 8 & 42.77 & 9.83 & 32.94 & 0.52 & $5,173.7$ & 1.89 & 294.8 \\
\hline $\begin{array}{l}\text { Rata- } \\
\text { rata }\end{array}$ & 41.34 & 9.98 & 31.36 & 0.59 & $5,926.8$ & 2.16 & 337.7 \\
\hline
\end{tabular}

\section{KESIMPULAN}

Berdasarkan peneilitian yang telah dilakukan maka dapat disimpulkan kandungan karbon tertinggi berada pada plot 4 yaitu sebesar 19,30 gram karbon dan kandungan karbon terendah berada pada plot 2 dengan jumlah karbon sebesar 9,43 gram karbon dengan rata-rata karbon serasah sebesar 467,37 gram. Untuk persentase kandungan karbon pada serasah mangrove tertinggi terdapat di plot 1 serasah sebesar $39,19 \% \quad \mathrm{C} / \mathrm{hr}$ dan peresentase kandungan karbon terendah berada pada plot 2 sebesar $24,49 \% \mathrm{C} / \mathrm{hr}$. Hasil estimasi rata-rata kandungan karbon (C) pada serasah daun mangrove di Desa Lansa Kecamatan Wori Kabupaten Minahasa Utara yaitu sebesar 2,16 ton/ha/tahun atau penyerapan $\left(\mathrm{CO}_{2}\right)$ sebesar 337,7 ton/tahun.

\section{DAFTAR PUSTAKA}

Bachmid, F. Sondak, CFA. Kusen, JD. 2017. Estimasi Penyerapan Karbon Hutan Mangrove Bawoho, Kecamatan Tongkaina, Kecamatan Bunaken. Jurnal Pesisir dan Laut Tropis 1(1):813

Chanan, M. 2012. Pendugaan Cadangan Karbon (C) Tersimpan Di Atas Permukaan Tanah Pada Vegetasi Hutan Tanaman Jati (Tectona Grandis Linn. F )(Di Rph Sengguruh Bkph Sengguruh Kph Malang Perum Perhutani li Jawa Timur). Jurnal Gamma. Vol 7. No 2. Hal 61-73.
Dharmawan, I. W. E, Zamani. N. P, dan Madduppa. H. H., 2016. Laju Dekomposisi Serasah Daun di Ekosistem Bakau Pulau Kelong, Kabupaten Bintan. Oseanologi dan Limnologi di Indonesia. Vol 1. No.1: Hal 1-10.

Hidayanto, W., Heru, A. dan Yossita. 2004. Analisis tanah tambak sebagai indikator tingkat kesuburan tambak. Jurnal Pengkajian dan Pengembangan Teknologi Pertanian.7 (2): $11 \mathrm{p}$.

Haris. A, Ario Damar, Dietiech G. Bengen dan Ferdinan Yulianda. 2012. Produksi Serasah mangrove dan Kontribusinya Terhadap Perairan Pesisir Kabupaten Sinjai. Vol 1. No 1: Hal 13-18.

Hamidy, R., S. Sastrodiharjo, Ardianto, Taufiturrahman. 2002. Struktur Komunitas dan Produksi Serasah Mangrove di Dumai, Riau, Biologi 2 (13):755-768

Heriyanto N.M. dan Endro Subiandono. 2012. Komposisi dan Struktur Tegakan, Biomasa, dan Potensi Kandungan Karbon Hutan Mangrove di Taman Nasional Alas Purwo. Jurnal Penelitian Hutan dan Konservasi Alam. Vol 9. No 1. Hal 2332.

Kathiresan K. dan B. L. Bingham 2001 Biology of Mangrove ekosistem. Avances in marine Biology. Vol 40: Hal 81-251

Manuri, S., Putra C.A.S. dan Saputra, A. D. 2011. Teknik pendugaan cadangan karbon hutan. Merang redd pilot project-german international cooperation (mrpp-giz). Palembang. 91p.

Paruntu C., A. Windarto, A. Rumengan. 2017. Karakteristik komunitas mangrove desa Motandoi kecamatan Pinolosian Timur kabupaten Bolaang Mongondow Selatan provinsi Sulawesi Utara. Jurnal Pesisir dan Laut Tropis. Vol. 1 No. 1: 5365.

Rumengan A. P., Mantiri D. M. H., Rompas R., Hutahaean A., Kepel T. L., Paruntu C. P., Kepel R. C., Gerung G. S., 2018 Carbon stock assessment of mangrove ecosystem in Totok Bay, southeast Minahasa Regency, North Sulawesi, Indonesia. AACL Bioflux 11(4):12801288.

Rudiansyah. R, Arief Pratomo dan Donny Apdillah. 2013. Analisis Laju Produksi Kandungan Karbon (C) Serasah Daun Mangrove Di Kampung Gisi Desa Tembeling Kabupaten Bintan. 1-9 hal

Rositah, Herawatiningsih H., dan Hardiansyah G. 2013. Pendugaan Biomassa Karbon Serasah Dan Tanah Pada Hutan Tanaman (Shorea leprosula Miq) Sistem TPTII PT. Suka Jaya Makmur. Vol 1 (3): hal 358-366

Rudiansyah. R, Arief Pratomo dan Donny Apdillah. 2013. Analisis Laju Produksi Kandungan Karbon (C) Serasah Daun Mangrove Di Kampung Gisi Desa Tembeling Kabupaten Bintan. 1-9 hal

Sondak, C.F.A. Sondak. 2015. Estimasi Potensi Penyerapan Karbon Biru (Blue Carbon) Oleh Hutan Mangrove Sulawesi Utara. Journal of ASEAN Studies on Maritime Issues. 1(1): 24-29

Verisandria R, J. Schaduw, C. Sondak, M. Ompi, A. Rumengan, J. Rangan. 2018. Estimasi Potensi Karbon Pada Sedimen Ekosistem Mangrove Di 
Pesisir Taman Nasional Bunaken Bagian Utara. Jurnal Pesisir dan Laut Tropis. Vol. 1 No. 1: Hal 81-97

Wiarta. R, Dwi Astiani, Yuliati I, Fairus M. 2017. Perdugaag Jumlah Karbon Tersimpan Pada Tegakan Jenis Bakau (Rhizophora apiculata BL) di IUPHHK PT. Bina Ovivipari Semesta Kabupaten Kubu Raya. Jurnal Hutan Lestari. Vol 5. No 2. Hal 356-364.

Yuniawati, Budiaman A. dan Elias. 2011. Estimasi Potensi Biomassa dan Massa Karbon Hutan
Tanaman Acacia crassicarpa Di Lahan Gambut. Jurnal Penelitian Hasil Hutan. 29 (4): 343 - 355.

Zamroni. Y. dan Immy. S.R. 2008. Produksi Serasah Hutan Mangrove di Perairan Pantai Teluk Sepi, Lombok Barat. Jurnal. Vol. 9. No 4. Hal 284-287.

Zulkarnain, Sitti Marwah. dan Lia Sartika. 2016. Sebaran Stok Karbon Vegatasi mangrove di Wilayah Pesisir Kecamatan Lainea Kabupaten Konawe Selatan Melalui Analisis Backscatter Citra Satelit radar Alos Plasar L-Band. Vol 2. No 2. Hal 97-105. 